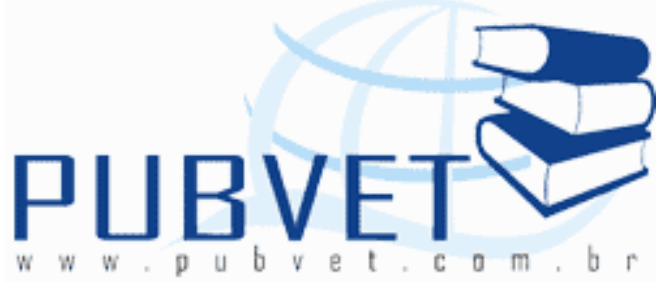

PUBVET, Publicações em Medicina Veterinária e Zootecnia.

\title{
Prevalência, etiologia, sensibilidade microbiana e fatores de risco associados à mastite no rebanho leiteiro bovino do Município de Alegre, Espírito Santo, Brasil
}

Igor Luiz Salardani Senhorello스, Alexandre de Oliveira Bezerra ${ }^{1}$, Romerí Pedro dos Santos ${ }^{1}$, Peter Gabriel Ferreira ${ }^{1}$, Renan Zappavigna Costa Starling ${ }^{1}$, Dirlei Molinari Donatele ${ }^{1}$, Renata Côgo Clipes $^{2}$

${ }^{1}$ Universidade Federal do Espírito Santo, Departamento de Medicina Veterinária; Alegre; Espírito Santo; Brasil.

${ }^{2}$ Instituto Federal do Espírito Santo; IFES-Campus Alegre; Alegre; Espírito Santo; Brasil.

\section{Resumo}

Objetivou-se avaliar as condições sanitárias do rebanho leiteiro do município de Alegre, ES, quanto à ocorrência, principais agentes etiológicos, perfil de sensibilidade microbiana e os fatores que podem favorecer o aparecimento da mastite. Foi realizado exame macroscópico do leite em 399 animais de 20 propriedades do município de Alegre, ES, no período de julho de 2010 a julho de 2011, utilizando-se o Califórnia Mastitis Test (CMT) e posteriormente, cultura das amostras CMT positivas e antibiograma com 21 antimicrobianos. Realizou-se também, uma entrevista estruturada aos proprietários referente à produção de leite, sanidade dos animais, procedimentos de ordenha e assistência técnica. Do total de animais avaliados, 37,9\% apresentaram CMT 

associados à mastite no rebanho leiteiro bovino do Município de Alegre, Espírito Santo, Brasil. PUBVET, Londrina, V. 7, N. 22, Ed. 245, Art. 1619, Novembro, 2013.

positivo, destes, houve crescimento bacteriano de 76,9\%, distribuído em Staphylococcus spp. (74,5\%), Corynebacterium spp. (18,8\%) e Streptococcus spp. (6,7\%). Pôde-se observar que há necessidade de melhorar as condições de manejo, como o uso adequado da ordenha mecânica. Considera-se também que a presença de orientação técnica por meio de médico veterinário permite a diminuição da mastite nos rebanhos bovinos, além da importância da realização do antibiograma, o que pode diminuir gastos com medicamentos e reduzir a indução de resistência de microorganismos. Dessa forma, sugere-se a aplicação dos programas de controle de mastite nas propriedades analisadas.

Palavras-chave: bovinos, mastite, antibiograma.

\title{
Prevalence, etiology, antimicrobial susceptibility and risk factors associated with mastitis in the dairy cattle herd from Alegre municipality, Espírito Santo, Brazil
}

\begin{abstract}
The purpose of this work was to avaliate sanitary conditions in dairy cows from Alegre, Espírito Santo State, relating to occurrence, main etiologic agents, rate of microbial sensibility and the facts that help mastitis occurrence. California Mastitis Test (CMT) was made in 399 animals from 20 farms located in Alegre, Espírito Santo State, from july 2010 to july 2011. Samples of CMT positives were microbiologicaly cultured and antibiogram test using 21 different antibiotics were done. Structured interviewing was done with farmers related to dairy production, animals sanity, milking procedures and technical assistance. From all animals studied, 37,9\% were CMT positives. From these in $76,9 \%$ bacterial growing were observed being 74,5\% Staphylococcus spp., $18,8 \%$ Corynebacterium spp. and $6,7 \%$ Streptococcus spp. Improving cattle management as proper using of mechanical milking is necessary. It is also observed that the presence of veterinarians with technical orientations allows to low mastitis in dairy cattle, besides the importance of antibiogram, lowing expences with medications and lowing induction of resistence by
\end{abstract}


SENHORELLO, I.L.S. et al. Prevalência, etiologia, sensibilidade microbiana e fatores de risco associados à mastite no rebanho leiteiro bovino do Município de Alegre, Espírito Santo, Brasil.

PUBVET, Londrina, V. 7, N. 22, Ed. 245, Art. 1619, Novembro, 2013.

microorganisms. Therefore, it is suggested to apply programs of mastitis control in farms studied

Keywords: bovine, mastitis, antibiogram.

\section{INTRODUÇÃO}

A mastite é uma das mais comuns e importantes doenças do rebanho leiteiro, causando diminuição na produção do animal, podendo causar danos permanentes a glândula mamária, além de depreciar a qualidade do leite (RIBEIRO et al., 2003).

No Brasil, a alta prevalência da mastite representa prejuízo de 12 a $15 \%$ na produção de leite (FAGUNDES \& OLIVEIRA, 2004). O grande impacto econômico deve ser ressaltado, principalmente, pelas perdas decorrentes na produção, alto custo com tratamento, perda de tetos, honorários veterinários, ou mesmo morte do animal (RIBEIRO JÚNIOR et al., 2008).

Conforme a sua manifestação, a doença pode ser classificada como subclínica e clínica. Na mastite subclínica não são observadas reações macroscópicas detectáveis, porém, com alterações químicas e microbiológicas do leite. A mastite clínica é marcada por respostas inflamatórias mais severas, que resultam em mudanças no aspecto da secreção láctea, mudanças visíveis no tecido mamário e, em alguns casos, efeitos sistêmicos como hipertermia, prostração e tremores musculares (PRESTES et al., 2003). Pode ser causada por agentes físicos, químicos, tóxicos, fisiológicos e infecciosos, sendo a de origem bacteriana a de maior prevalência (FREITAS et al., 2005).

Segundo Ribeiro et al. (2008) dois diferentes grupos de microorganismos são responsáveis por causar a mastite: contagiosos e ambientais. A mastite causada por microorganismos contagiosos é a de maior importância por não ser autolimitante, podendo assumir um caráter crônico. A transmissão ocorre durante a ordenha de uma glândula mamária infectada para outra, sendo esse tipo de microorganismo bem adaptado a sobreviver no úbere (exs. Staphylococcus aureus, Staphylococcus coagulase negativo, Corynebacterium spp.). Os microorganismos ambientais possuem como característica serem 
SENHORELLO, I.L.S. et al. Prevalência, etiologia, sensibilidade microbiana e fatores de risco associados à mastite no rebanho leiteiro bovino do Município de Alegre, Espírito Santo, Brasil.

PUBVET, Londrina, V. 7, N. 22, Ed. 245, Art. 1619, Novembro, 2013.

oportunistas, estando presentes no ambiente do animal, com isso, podem causar infecção principalmente entre ordenhas (exs. Escherichia coli, Proteus spp., Klebsiella spp.). O gênero Streptococcus spp. possui subgêneros específicos para os dois grupos (BUENO et al., 2003).

o exame microbiológico é considerado o método padrão para determinação da saúde do úbere e para o diagnóstico da mastite bovina, sendo que o seu principal objetivo é oferecer resultados rápidos e seguro ao médico veterinário, para que ele possa identificar os problemas do rebanho (MONTESINOS et al., 2002).

Por outro lado, a presença da mastite no rebanho leiteiro faz com que os gastos com medicamentos sejam elevados, pois muitas vezes esses medicamentos são escolhidos de maneira aleatória. A escolha de antibióticos adequados e eficientes deve ser criteriosa e sempre que possível baseada em resultados de testes de sensibilidade (PRESTES et al., 2002).

O uso indiscriminado de antimicrobianos tem favorecido a seleção de cepas resistentes, o que ressalta a importância de levantamentos periódicos quanto à resistência bacteriana dos agentes causadores da mastite (BARBERIO et al., 2002). O antibiograma é um método de tipagem bacteriana útil e complementar ao exame microbiológico. Esse exame contribui na identificação in vitro da resistência e sensibilidade bacteriana aos antimicrobianos, direcionando assim, o tratamento mais adequado para a mastite bacteriana, podendo ser utilizada com várias espécies de microorganismos.

Outro aspecto importante trata-se dos estudos epidemiológicos sobre fatores de risco que podem identificar características relacionadas ao animal, ao ambiente, aos procedimentos de manejo e ao equipamento de ordenha, associadas à mastite bovina (SOUZA et al., 2005).

Dessa forma, objetivou-se avaliar as condições sanitárias do rebanho leiteiro do município de Alegre, ES, quanto à prevalência de mastite, a etiologia infecciosa, a sensibilidade microbiana e os fatores de riscos associados. 


\section{MATERIAL E MÉTODOS}

O trabalho de pesquisa foi realizado em 20 propriedades de bovinos leiteiros do município de Alegre, ES, selecionadas aleatoriamente, as quais estavam cadastradas na Secretaria Municipal de Agricultura do município.

Após os procedimentos iniciais para a ordenha de cada propriedade, foi realizado o California Mastitis Test (CMT) para a deteç̧ão da mastite subclínica, perfazendo um total de 399 vacas, predominantemente mestiças zebuínas, no período de julho de 2010 a julho de 2011.

Foram coletados $05 \mathrm{~mL}$ de leite dos animais, de cada quarto que apresentavam CMT positivos, em tubos estéreis, previamente identificados, para a realização de exames microbiológicos. Os tubos foram acondicionados em caixas isotérmicas com gelo e conduzidos ao Laboratório de Inspeção de Produtos de Origem Animal do Centro de Ciências Agrárias da Universidade Federal do Espírito Santo.

As amostras de leite foram inoculadas em meios de cultura não seletivos, e incubadas a $37^{\circ} \mathrm{C}$, por 24 a 48 horas, para realização do isolamento e identificação dos microorganismos, conforme Quinn et al. (2005).

Para o estudo do perfil de resistência aos antimicrobianos in vitro, os isolados foram submetidos à técnica de difusão de discos em placas conforme descrito por Bauer et al. (1966), utilizando-se os seguintes antibióticos:

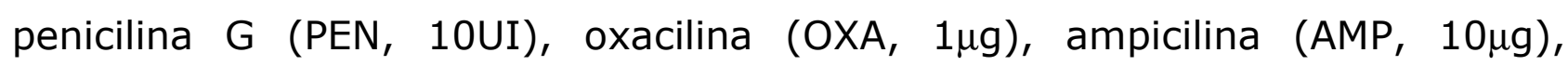

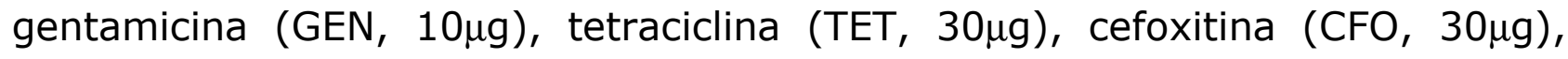

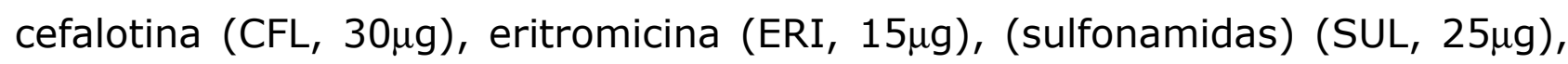

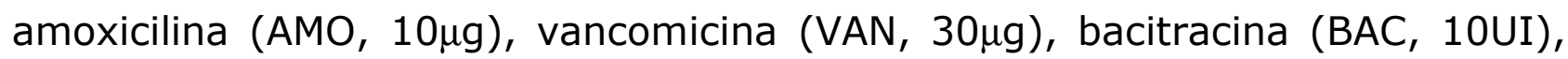

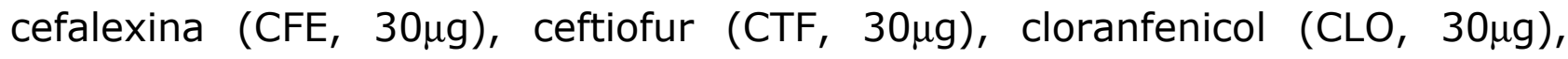

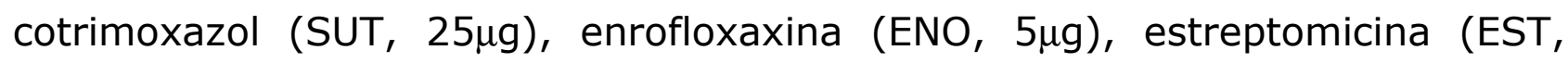
$10 \mu \mathrm{g})$, florfenicol $(\mathrm{FLF}, 30 \mu \mathrm{g})$, neomicina (NEO, 30 $\mathrm{g}$ ), norfloxacina (NOR, $10 \mu \mathrm{g})$.

Foi aplicado a todos os proprietários ou responsáveis pelas propriedades uma entrevista estruturada abordando variáveis referentes à produção de 
SENHORELLO, I.L.S. et al. Prevalência, etiologia, sensibilidade microbiana e fatores de risco associados à mastite no rebanho leiteiro bovino do Município de Alegre, Espírito Santo, Brasil.

PUBVET, Londrina, V. 7, N. 22, Ed. 245, Art. 1619, Novembro, 2013.

leite, controle e sanidade dos animais, procedimentos de ordenha e assistência técnica.

Os dados foram tabulados, e posteriormente foi realizado o teste do Quiquadrado com correção de Yates (SAMPAIO, 1998).

\section{RESULTADOS E DISCUSSÃO}

Do total de animais testados, 37,9\% (151) apresentaram CMT positivo, indicativo de mastite, sendo $7,3 \%$ (11) na forma clínica, evidenciada pela presença de grumos, e 92,7\% (140) na forma subclínica, apresentando uma relação de 1:13 entre mastite clínica e subclínica. A prevalência encontrada nesse estudo foi semelhante ao encontrado por Ribeiro et al. (2003) no Sul do Rio Grande do Sul, onde encontraram uma prevalência de $37,69 \%$ de mastite. Com relação ao tipo de mastite foi encontrado uma maior prevalência de mastite subclínica no rebanho estudado o que corrobora com achados de Martins et al. (2010) e uma relação entre mastite clínica e subclínica semelhante aos estudos de Martins et al. (2010) e Bueno et al. (2003), onde os mesmo encontraram uma relação de 1:11 e 1:15, respectivamente.

Das 311 amostras dos quartos positivos analisadas microbiologicamente, $239(76,9 \%)$ apresentaram crescimento bacteriano, na qual 74,5\% (178) eram do gênero Staphylococcus spp., prevalecendo Staphylococcus coagulase positiva em 43,5\% (104) das amostras, seguidos de Staphylococcus coagulase negativa em 31\% (74), 18,8\% (45) do gênero Corynebacterium spp., e 6,7\% (16) do gênero Streptococcus spp.. No Brasil, diversos estudos (BUENO et al., 2003; FERREIRA et al., 2007) relataram a presença da mastite nos rebanhos bovinos, com predominância dos agentes Staphylococcus spp. e Corynebacterium spp.. O gênero Corynebacterium spp. apresenta crescimento lento (BIGGS, 2009), dessa forma, optou-se por não realizar o antibiograma para o mesmo.

$\mathrm{Na}$ Tabela 1 verifica-se que o gênero Staphylococcus spp. apresentou resistente à amoxacilina (51,6\%), ampicilina $(53,9 \%)$ e penicilina $\mathrm{G}(57,3 \%)$. 
A resistência verificada para os betalactâmicos (amoxicilina, ampicilina e penicilina G) foi verificada por outros autores (BYARUGABA et al., 2004; FREITAS et al., 2005; FERREIRA et al., 2010). Esta resistência pode estar associada ao uso indiscriminado e inadequado (subdosagens) na prática médico veterinária, o que possibilita a seleção de cepas resistentes, e, pela presença da enzima ß-lactamase que consegue romper o anel betalactâmico, uma estrutura molecular fundamental para a ação deste antibiótico (SANTOS et al., 2007).

A oxacilina, embora seja um betalactâmico, apresentou eficácia acentuada para ambos os Staphylococcus spp. (Tabela 1), isto se deve ao fato de ser uma penicilina resistente às penicilinases produzidas pelos Staphylococcus spp. (HARDMAN, 1996).

O sucesso no tratamento da mastite estafilocócica, principalmente no caso da gentamicina (91\%), como sugerido e apresentado na Tabela 1 é confirmado por vários autores (OLIVEIRA et al., 2002, BYARUGABA et al., 2004), contudo, em função do uso excessivo deste antibiótico no agreste de Pernambuco, Freitas et al. (2005) verificaram alto nível de resistência dos Staphylococcus spp. à gentamicina, destacando o problema do uso indiscriminado e a seleção de bactérias resistentes.

A estreptomicina (Tabela 1) apresentou eficácia contra os causadores da mastite bovina, discordando dos resultados encontrados por Ferreira et al. (2010), isto é possível visto que os genes que conferem à resistência podem estar associados à plasmídios conjugativos e não conjugativos e em transposons, não sendo induzidos pela presença do antimicrobiano (SILVA; CARVALHO, 2007).

A tetraciclina apresentou eficácia de 70,8\% (Tabela 1) contra os isolados de Staphylococcus spp. e 100\% dos Streptococcus spp., contudo, Spinosa (1996) recomenda atenção em seu uso, pois a resistência antimicrobiana é mediada principalmente por plasmídios, podendo carrear resistência para outras bactérias. Segundo Medeiros et al. (2009) as ações promovidas por 
SENHORELLO, I.L.S. et al. Prevalência, etiologia, sensibilidade microbiana e fatores de risco associados à mastite no rebanho leiteiro bovino do Município de Alegre, Espírito Santo, Brasil.

PUBVET, Londrina, V. 7, N. 22, Ed. 245, Art. 1619, Novembro, 2013.

genes de resistência plasmidial são muito efetivas, pois se baseiam quase sempre, na produção de enzimas.

Tabela 1 - Sensibilidade dos principais gêneros bacterianos causadores de mastite bovina, conforme os antibióticos testados no período de julho de 2010 a julho de 2011 no município de Alegre, Espírito Santo.

\begin{tabular}{|c|c|c|c|c|c|c|}
\hline \multirow[t]{2}{*}{ Antibiótico } & \multicolumn{3}{|c|}{ Staphylococcus spp. (n/\%) } & \multicolumn{3}{|c|}{ Streptococcus spp. (n/\%) } \\
\hline & $\mathrm{S}$ & I & $\mathrm{R}$ & $\mathrm{S}$ & I & $\mathrm{R}$ \\
\hline Amoxicilina & $86 / 48,4$ & - & $92 / 51,6$ & $16 / 100$ & - & - \\
\hline Ampicilina & $82 / 46.1$ & - & $96 / 53,9$ & $16 / 100$ & - & - \\
\hline Bacitracina & $160 / 89,9$ & $03 / 1,7$ & $15 / 8,4$ & $15 / 93,8$ & - & $01 / 6,2$ \\
\hline Cefalexina & $171 / 96,0$ & $04 / 2,3$ & $03 / 1,7$ & $15 / 93,8$ & - & $01 / 6,2$ \\
\hline Cefalotina & $170 / 95,5$ & $03 / 1,7$ & $04 / 2,3$ & $15 / 93,8$ & - & $01 / 6,2$ \\
\hline Cefoxitina & $168 / 94,4$ & - & $10 / 5,6$ & $15 / 93,8$ & - & $01 / 6,2$ \\
\hline Ceftiofur & $169 / 94,9$ & $06 / 3,4$ & $02 / 1,1$ & $16 / 100$ & - & - \\
\hline Cloranfenicol & $162 / 91,0$ & $08 / 4,5$ & $08 / 4,5$ & $15 / 93,8$ & - & $01 / 6,2$ \\
\hline Cotrimoxazol & $170 / 95,5$ & $01 / 0,6$ & $07 / 3,9$ & $16 / 100$ & - & - \\
\hline Enrofloxacina & $163 / 91,6$ & $10 / 5,6$ & $05 / 2,8$ & 16100 & - & - \\
\hline Eritromicina & $158 / 88,8$ & $14 / 7,9$ & $06 / 3,4$ & $15 / 93,8$ & - & $01 / 6,2$ \\
\hline Estreptomicina & $143 / 80,3$ & $16 / 9,0$ & $19 / 10,7$ & $11 / 68,8$ & - & $05 / 31,2$ \\
\hline Florfenicol & $168 / 94,4$ & $04 / 2,3$ & $06 / 3,4$ & $16 / 100$ & - & - \\
\hline Gentamicina & $162 / 91,0$ & $07 / 3,9$ & $09 / 5,1$ & $16 / 100$ & - & - \\
\hline Neomicina & $163 / 91,6$ & $12 / 6,7$ & $03 / 1,7$ & $16 / 100$ & - & - \\
\hline Norfloxacino & $169 / 94,9$ & $02 / 1,1$ & $07 / 3,9$ & $15 / 93,8$ & - & $01 / 6,2$ \\
\hline Oxacilina & $153 / 86,0$ & $08 / 4,6$ & $16 / 9,0$ & $15 / 93,8$ & - & $01 / 6,2$ \\
\hline Penicilina G & $75 / 42,1$ & $01 / 0,6$ & $102 / 57,3$ & $14 / 87,6$ & $1 / 6,2$ & $01 / 6,2$ \\
\hline Sulfazotrim & $112 / 62,9$ & $21 / 11,8$ & $45 / 25,3$ & $11 / 68,8$ & - & $05 / 31,2$ \\
\hline Tetraciclina & $126 / 70,8$ & $12 / 6,7$ & $40 / 22,5$ & $16 / 100$ & - & - \\
\hline Vancomicina & $169 / 94,9$ & $01 / 0,6$ & $08 / 4,5$ & $15 / 93,8$ & - & $01 / 6,2$ \\
\hline
\end{tabular}

S: Sensível; I: Intermediário; R: Resistente.

Staphylococcus spp. $\mathrm{n}=178$

Streptococcus spp. $\mathrm{n}=16$ 
O cloranfenicol, embora tenha apresentado sensibilidade acentuada frente aos Staphylococcus spp. e Streptococcus spp., também confirmado por Ferreira et al. (2010), seu uso é proibido devido ao efeito toxicológico, e, provavelmente, essa baixa resistência seja pela ausência de pressão seletiva em função da sua baixa utilização.

No grupo das cefalosporinas, cefalotina, cefoxitina e a cefalexina apresentaram eficácia para o gênero Staphylococcus spp., sendo o mesmo relatado por Oliveira et al. (2011) para a cefalotina e cefoxitina, e por Souza et al. (2008) utilizando-se a cefalexina.

A utilização da bacitracina apresentou eficácia para Staphylococcus spp. e Streptococcus spp., o que foi observado por Cunha et al. (2006) para o gênero Streptococcus spp.

O gênero Staphylococcus spp. apresentou elevada sensibilidade para o ceftiofur e a enrofloxacina, $94,9 \%$ e $91,6 \%$, respectivamente e ambos obtiveram eficácia de $100 \%$ para ao gênero Streptococcus spp.. Moreira et al. (1997), verificaram um espectro de sensibilidade acentuado para a enrofloxacina (96\%) e ceftiofur (94\%) para o Staphylococcus coagulase positiva e Streptococcus spp., resultados estes, obtidos quando os princípios ativos, ainda eram recentes no mercado, o que comprova a eficácia destes antimicrobianos podendo estar relacionado com uso controlado destes produtos.

Ambos os gêneros apresentaram acentuada sensibilidade para o florfenicol, o que foi verificado por outros autores (DOMINGUES et al. 2006; MEDEIROS et al. 2009). Silva et al. (2010) relata sua eficiência de $100 \%$ frente aos isolados Gram positivos e intitulou o florfenicol como um dos melhores antimicrobianos para o gênero Streptococcus spp..

O cotrimoxazol apresentou eficácia superior a 95,5\% (Tabela 1), tanto para o gênero Staphylococcus spp., quanto para Streptococcus spp., no entanto, Schmidt et al. (2009) verificaram resistência de $50 \%$ das linhagens de Staphylococcus coagulase negativa causadores de mastite caprina ao Cotrimoxazol, criadas em sistema orgânico. 
SENHORELLO, I.L.S. et al. Prevalência, etiologia, sensibilidade microbiana e fatores de risco associados à mastite no rebanho leiteiro bovino do Município de Alegre, Espírito Santo, Brasil.

PUBVET, Londrina, V. 7, N. 22, Ed. 245, Art. 1619, Novembro, 2013.

Os gêneros Staphylococcus spp. e Streptococcus spp. apresentaram sensibilidade acentuada (88,8\% e $93,8 \%$ respectivamente) para a eritromicina, concordando com Ferreira et al. (2010). No entanto, Oliveira et al. (2011), ao trabalhar com a mastite bovina na bacia leiteira de Rondon do Pará, obtiveram reação intermediária de 52,2\% do gênero Staphylococcus spp. coagulase negativo, e de 53,3 \% Staphylococcus spp. coagulase positiva, além disso, $50 \%$ dos Streptococcus spp. foram resistentes.

A neomicina apresentou eficácia de $91,6 \%$ para os Staphylococcus spp. e $100 \%$ para os Streptococcus spp.. Isto contrasta com Souza et al. (2008) em que o gênero Staphylococcus spp. foi resistente a neomicina na região de Garça, SP. Quando utilizada em associação com a bacitracina e tetraciclina, a neomicina apresentou $100 \%$ de sensibilidade em relação ao Staphylococcus aureus e Staphylococcus Coagulase negativo (NEVES et al. 2010).

A norfloxacina apresentou eficácia de $94,9 \%$ para o gênero Staphylococcus spp. e 93,8\% para Streptococcus spp.. Neves et al. (2010) relata que $83,33 \%$ dos Staphylococcus coagulase negativo foram sensíveis a norfloxacina. E a Vancomicina demonstrou eficácia para os ambos os gêneros apresentando elevados índices de eficácia. Isto discorda de Ferreira et al. (2010), na qual apenas 34,32\% das estirpes de Staphylococcus spp., e $25 \%$ de Streptococcus spp foram sensíveis à Vancomicina. Por outro lado, Nader Filho et al. (2007) verificaram que $72,2 \%$ das amostras foram sensíveis à vancomicina em teste de sensibilidade para Staphylococcus aureus.

Ao avaliar os fatores de risco relacionados à mastite (Tabela 2 ) verificouse que o uso da ordenhadeira mecânica foi associado à presença de mastite $(p<0,05)$, em que o bovino ordenhado mecanicamente apresenta risco de 3,662 (Odds Ratio) vezes maior de adquirir mastite subclínica em comparação aos ordenhados manualmente (Tabela 2). Da mesma forma, Oliveira et al. (2010) relataram que o uso de ordenhadeira mecânica foi associada à presença de mastite $(p=0,039)$.

Conforme Reis et al. (2007), isto ocorre, provavelmente pela possibilidade de falhas no equipamento, caracterizadas por alterações de 
SENHORELLO, I.L.S. et al. Prevalência, etiologia, sensibilidade microbiana e fatores de risco associados à mastite no rebanho leiteiro bovino do Município de Alegre, Espírito Santo, Brasil.

PUBVET, Londrina, V. 7, N. 22, Ed. 245, Art. 1619, Novembro, 2013.

vácuo, pulsação, sobreordenha, deslizamento de teteiras e deficiência de desinfecções, que podem comprometer a integridade das células que revestem o canal do teto.

Tabela 2 - Números de animais conforme diagnóstico da mastite segundo as variáveis relacionadas a fatores de risco, respectivos valores de Odds Ratio (OR) e a probabilidade de ocorrência $(P)$ provenientes do município de Alegre, Espírito Santo.

\begin{tabular}{|c|c|c|c|c|c|c|}
\hline \multirow{2}{*}{ Variáveis } & \multicolumn{2}{|c|}{$\begin{array}{l}\text { Bovinos } \\
\text { Positivos } \\
\end{array}$} & \multicolumn{2}{|c|}{$\begin{array}{l}\text { Bovinos } \\
\text { Negativos }\end{array}$} & \multirow{2}{*}{$\begin{array}{l}\text { Odds Ratio } \\
\text { (IC 95\%) }\end{array}$} & \multirow{2}{*}{$\mathrm{P}$} \\
\hline & $\mathrm{n}$ & $\%$ & $n$ & $\%$ & & \\
\hline \multicolumn{7}{|c|}{ Bezerro ao pé } \\
\hline Sim & 140 & 37,3 & 235 & 62,7 & & \\
\hline Não & 11 & 45,8 & 13 & 54,2 & 1.433 & 0.6044 \\
\hline \multicolumn{7}{|c|}{ Ordenha Mecânica } \\
\hline Sim & 48 & 63,2 & 28 & 36,8 & & \\
\hline Não & 103 & 31,9 & 220 & 68,1 & 3.662 & 0.000000426 \\
\hline \multicolumn{7}{|c|}{$\begin{array}{c}\text { Desinfecção dos } \\
\text { tetos }\end{array}$} \\
\hline Sim & 5 & 73,5 & 4 & 26,5 & & \\
\hline Não & 146 & 32,9 & 244 & 67,1 & 2.089 & 0.2689 \\
\hline \multicolumn{7}{|l|}{$\begin{array}{l}\text { Profilaxia do } \\
\text { ordenhador }\end{array}$} \\
\hline Sim & 5 & 55,6 & 4 & 44,4 & & \\
\hline Não & 146 & 37,4 & 244 & 62,6 & 2.089 & 0.2689 \\
\hline \multicolumn{7}{|l|}{ Uso CMT } \\
\hline Sim & 34 & 33,0 & 69 & 67,0 & & \\
\hline Não & 117 & 39,5 & 179 & 60,5 & 0.7539 & 0.2408 \\
\hline \multirow{2}{*}{\multicolumn{7}{|c|}{$\begin{array}{l}\text { Presença } \\
\text { Veterinária }\end{array}$}} \\
\hline & & & & & & \\
\hline Sim & 78 & 32,6 & 161 & 67,4 & & \\
\hline Não & 73 & 45,6 & 87 & 54,4 & 0.5774 & 0.008745 \\
\hline
\end{tabular}

A presença de médico veterinário também foi um fator relevante (Tabela 2), mostrando que animais que receberam assistência de médico veterinário apresentaram menores percentuais de infecção $(p<0,05)$, assumindo essa variável um fator protetor, na qual animais que recebem assistência possuem menores riscos de infecção (Odds Ratio $=0.5774$ ). Observa-se em trabalho 
SENHORELLO, I.L.S. et al. Prevalência, etiologia, sensibilidade microbiana e fatores de risco associados à mastite no rebanho leiteiro bovino do Município de Alegre, Espírito Santo, Brasil.

PUBVET, Londrina, V. 7, N. 22, Ed. 245, Art. 1619, Novembro, 2013.

realizado por Oliveira et al. (2010) que animais que receberam assistência veterinária apresentaram menores percentuais de infecção $(p=0,012)$, o que demonstra a importância da presença desse profissional na indução de medidas profiláticas e de controle do rebanho visando à manutenção da sanidade.

Animais que receberam higienização dos tetos antes e após a ordenha, e eram tratados por ordenhadores que realizavam profilaxia ao manejá-los, não diferiram $(p>0,05)$, quanto à presença da mastite, perante aqueles que estavam em propriedade, onde não se fazia a higienização (Tabela 2). Por outro lado, estudos demonstraram que a alta prevalência da mastite está associada às más condições de higiene do ordenhador, bem como dos tetos e úberes das vacas antes, durante e após a ordenha (FERREIRA et al., 2007).

Em relação ao uso do CMT (Tabela 2) não foi verificado diferença significativa $(p>0,05)$, o que foi verificado também em trabalho realizado por Oliveira et al. (2010). Por outro lado, é necessário relatar que o uso do CMT permite a detecção de vacas indicativas da mastite subclínica, auxiliando no manejo de linha de ordenha e até mesmo no envio de amostras de leite para análises microbiológicas.

O uso do bezerro ao pé não apresentou diferença significativa $(p>0,05)$, o que também foi verificado por Brandão et al. (2008) que relatou a possibilidade deste resultado estar relacionado ao padrão racial do rebanho utilizado, pois em ambos os estudos houve predominância de vacas mestiças zebu.

Dessa forma, conclui-se que há necessidade de melhorar as condições de manejo, como o uso da ordenha mecânica de forma adequada, visando diminuir a disseminação de microorganismos. Orientação técnica por meio de médico veterinário pode permitir a diminuição da mastite nos rebanhos bovinos, por meio da capacitação e identificação de possíveis problemas. E por fim, a realização do antibiograma é de extrema importância, o que poderá diminui os gastos com medicamentos e reduz a indução de resistência de microorganismos. 
SENHORELLO, I.L.S. et al. Prevalência, etiologia, sensibilidade microbiana e fatores de risco associados à mastite no rebanho leiteiro bovino do Município de Alegre, Espírito Santo, Brasil. PUBVET, Londrina, V. 7, N. 22, Ed. 245, Art. 1619, Novembro, 2013.

\section{AGRADECIMENTOS}

A Fundação de Amparo a Pesquisa do Espírito Santo (FAPES).

\section{REFERÊNCIAS}

BARBERIO, A.; GIETL, H.; DALVIT, P. "In vitro" sensibilidade aos antimicrobianos e Staphylococcus aureus e coliformes isolados de mastite bovina na região de Veneto, Itália, no período de 19961999. Napgama, v.5, n.1, p.10, 2002.

BAUER A.W., KIRBY W.M.M., SHERRIS J.C., TURCK M. Antibiotic susceptibility testing by a standardized single disk method. American Journal of Clinical Pathology, v.45, p.493-496, 1966.

BRANDÃO, F.P.; RUAS, J.R.M.; SILVA FILHO, J.M.; BORGES, L.E.; FERREIRA, J.J.; CARVALHO, B.C.; ALBERTO MARCATTI NETO, A.M.; AMARAL, R. Influência da presença do bezerro no momento da ordenha sobre o desempenho produtivo e incidência de mastite subclínica em vacas mestiças holandês-zebu e desempenho ponderal dos bezerros. Revista Ceres, v.55, n.6, p.525-531, 2008.

BIGGS, Andrew, Mastitis in catle. Marlborough: The Crowood Press, 192p.

BUENO, V.F.F.; NICOLAU, E.S.; MESQUITA, A.J.; RIBEIRO, A.R.; SILVA, J.A.B.; COSTA, E.O.; COELHO, K.O.; COUTO, D.V. Etiologia e suscetibilidade à antimicrobianos dos agentes da mastite bovina isolados na região de Pirassununga-SP-Brasil. Revista de Patologia Tropical, v.32, n.1, p.33-44, 2003.

BYARUGABA, D. K. A view on antimicrobial resistance in developing countries and responsible risk factors. International Journal of Antimicrobial Agents, Uganda, v.24, p.105-110, 2004.

CUNHA, A. P.; SILVA, L. B. G.; PINHEIRO JUNIOR, J. W.; SILVA, D. R.; OLIVEIRA, A. A. F.; SILVA, K. P. C.; MOTA, R. A. Perfil de sensibilidade antimicrobiana de agentes contagiosos e ambientais isolados de mastite clinica e subclínica de búfalas. Arquivo do Instituto Biológico, v.73, n.1, p.17-21, 2006.

DOMINGUES, P. F.; LUCHEIS, S. B.; SERRÃO, L. S.; FERNANDES, S.; CONTENTE, A. P. A.; MARTINS, E. C. V.; LANGONI, H. Etiologia e Sensibilidade Bacteriana da Mastite Subclínica em Ovelhas da Raça Santa Inês. Arquivos de Veterinária, Jaboticabal, SP, v.22, n.2, p.146-152, 2006.

FAGUNDES, H.; OLIVEIRA, C.A.F. Infecções intra-mamárias causadas por Staphylococcus aureus e sua implicações em saúde pública. Ciência Rural, v.3, n.4, p.1315-1320, 2004.

FERREIRA, J.L.; LINS, J.L.F.H.A.; CAVALCANT, T.V.; MACEDO, N.A.; BORJAS, A.R. Prevalência e etiologia da mastite bovina no município de Teresina, Piauí. Ciência Animal Brasileira, v.8, n.2, p.261-266, 2007.

FERREIRA, J. L.; PIGATTO, C. P.; LiNS, J. L. F. H. A.; AGUiAR FILHO, J. L. C.; CAVALCANTE, T. V. Bactérias causadoras de mastite subclínica em rebanhos leiteiros no município de Teresina, Piauí. Revista Científica Eletrônica de Medicina Veterinária. n.14, 2010. Disponível em: http://www.revista.inf.br/veterinaria14/artigos/RCEMV-AnoVIII-Edic14-Art08.pdf. Acesso em 31 de julho de 2010. 
FREITAS, M. F. L.; PINHEIRO JR, J. W.; STAMFORD, T. L. M.; RABELO, S. S. A.; SILVA, D. R.; SILVEIRA FILHO, V. M. S.; SANTOS, F. G. B.; SENA, M. J.; MOTA, R. A. Perfil de sensibilidade antimicrobiana in vitro de Staphylococcus coagulase positivos isolados de leite de vacas com mastite no agreste do estado de Pernambuco. Arquivos do Instituto Biológico, São Paulo, v.72, n.2, p.171-177, 2005.

HARDMAN, J.G.; LIMBIRD, L.E.; MOLINOFF, P.B.; RUDDON, R.W.; GILMAN, A.G. - Goodman \& Gilman - As Bases Farmacológicas da Terapêutica. McGraw Hill, 9a ed., 1996.

MARTINS, R.P; SILVA, J.A.G.; NAKAZATO, L. Prevalência e etiologia infecciosa da mastite bovina na microrregião de cuiabá, MT. Ciência Animal Brasileira, Goiânia, v. 11, n. 1, p. 181-187, 2010.

MEDEIROS, E. S.; MOTA, R. A.; SANTOS, M. V.; FREITAS, M. F. L.; PINHEIRO JR, J. W.; TELES, J. A. A. Perfil de sensibilidade microbiana in vitro de linhagens de Staphilococcus spp. isolados de vacas com mastite subclínica. Pesquisa Veterinária Brasileira, v.29, n.7, p.569574, 2009.

MONTESINOS I.; SALIDO E.; DELGADO T.; CUERVO M.; SIERRA A. Epidemiologic genotyping of methicillin-resistant Staphylococcus aureus by pulsedfield gel electrophoresis at a University Hospital and comparison with antibiotyping and protein A and coagulase gene polymorphisms. Journal of Clinical Microbiology, v.40, n.6, p.2119-2125, 2002.

MOREIRA, P. C.; SILVA, L. A. F.; MESQUITA, A. J. Resistência de Staphylococcus coagulase positiva e Streptococcus SP. Isolados do leite de vacas com mastite clínica na bacia leiteira de Goiânia. Pesquisa Agropecuária Tropical, v.27, n.2, 1997.

NADER FILHO, A.; FERREIRA, L. M.; AMARAL, L. A.; ROSSI JR, O. D.; OlIVEIRA, R. P. Sensibilidade Antimicrobiana dos Staphylococcus aureus isolados no leite de vacas com mastite. Arquivos do Instituto Biológico, São Paulo, v.74, n.1, p. 1-4, 2007.

NEVES P. B.; MEDEIROS E. S.; SÁ V. V.; CAMBOIM E. K. A.; GARINO JR F.; MOTA R. A.; AZEVEDO S. S. Perfil microbiológico, celular e fatores de risco associados à mastite subclínica em cabras no semiárido da Paraíba. Pesquisa Veterinária Brasileira, v.30 n.5, p.379-384, 2010.

OliveirA, A. A. F.; MOTA, R. A.; SOUZA, M. I.; SÁ M. E. P. Perfil de sensibilidade antimicrobiana in vitro frente a amostras de Staphylococcus spp. isolados de mastite subclínica bovina, no agreste meridional de Pernambuco. A Hora Veterinária. Porto Alegre, v.22, n.127, p.8-10, 2002.

OLIVEIRA, U. V.; GALVÃO, G. S.; PAIXÃO, A. R. R.; MUNHOZ, A. D. Ocorrência, etiologia infecciosa e fatores de risco associados à mastite bovina na microrregião Itabuna-Ilhéus, Bahia. Revista Brasileira de Saúde e Produção Animal, v.11, n.3, p.630-640, 2010.

OLIVEIRA, C. M. C.; SOUSA, M. G. S.; SILVA, N. S.; MENDONÇA, C. L.; SILVEIRA, J. A. S.; OAIGEN, R. P.; ANDRADE, S. J. T.; BARBOSA, J. D. Prevalência e etiologia da mastite bovina na bacia leiteira de Rondon do Pará, estado do Pará. Pesquisa Veterinária Brasileira, v.31, n.2, p.104-110, 2011.

PRESTES, D.S.; FILAPPI, A.; CECIM, M. Susceptibilidade à mastite: Fatores que influenciam uma revisão. Revista da Faculdade de Zootecnia, Veterinária e Agronomia. Uruguaiana, v.9, n.1, p.48-59, 2002. 
PRESTES, D. S.; FILAPPI, A.; CECIM, M. Susceptibilidade à mastite: fatores que a influenciam uma revisão. Revista da Faculdade de Zootecnia, Veterinária e Agronomia, v.9, n.1, p. 4859, 2003.

QUINN, P.J.; MARKEY B.K.; CARTER, M.E.; DONNELLY W.J.; LEONARD F.C. Microbiologia Veterinária e doenças infecciosas. Porto Alegre: Editora Artmed, 2005. 512p.

REIS, G.L.; ALVES, A.A.; LANA, A.M.Q.; COELHO, S.G.; SOUZA, M.R.; CERQUEIRA, M.M.O.P.; PENNA, C.F.A.M.; MENDES, E.D.M. Procedimento de coleta de leite cru individual e sua relação com a composição físico química e a contagem de células somáticas. Ciência Rural, v.37, n.4, p.1134-1138, 2007.

RIBEIRO, M.E.R.; PETRINI, L.A.; AITA, M.F.; BALBINOTTI, M.; STUMPF JÚNIOR, W.G.J.F.L.; SCHRAMM, R.C.; BARBOSA, R.S. Relação entre mastite clínica, subclínica infecciosa e não infecciosa em unidades de produção leiteiras na região sul do Rio Grande do Sul. Revista Brasileira de Agrociências, v.9, n.3, p.287-290, 2003.

RIBEIRO JÚNIOR, E., SILVA, M.H.; VIEGAS, S. A.A.RAMALHO, E. J.; RIBEIRO, M. D.; OLIVEIRA, F.C. S. California Mastitis Test (CMT) e whiteside como métodos de diagnóstico indireto da mastite subclínica. Revista Brasileira de Saúde Produção Animal, v.9, n.4, p. 680-686, 2008.

SANTOS, A.L.; SANTOS, D.O.; FREITAS, C.C.; FERREIRA, B.L.A.; AFONSO, I.F.; RODRIGUES, C.R.; CASTRO, H.C. Staphylococcus aureus: visitando uma cepa de importância hospitalar. Brazilian Journal of Pathology and Laboratory Medicine, v.43, n.6, p.413-423, 2007.

SAMPAIO, I.B.M. (Ed.). Estatística aplicada à experimentação animal. Belo Horizonte: Fundação de Ensino e Pesquisa em Medicina Veterinária e Zootecnia, 1998. 221p.

SCHMIDT, V.; PINTO, A. T.; SCHNEIDER, R. N.; SILVA, F. F. P. S.; MELLO, F. A. Caracterização da mastite subclínica em caprinos produzidos em sistema orgânico no Rio Grande do Sul. Pesquisa Veterinária Brasileira. v.29, n.9, p.774-778, 2009.

SILVA, G. J.; CARVALHO, I. new insights into aminoglycoside antibiotics and derivates. Current Medicinal Chemistry, v.14, n.10, p.1101-1119, 2007.

SILVA, N. S.; SILVEIRA, J. A. S.; PINHEIRO, C. P.; SOUSA, M. G. S.; OLIVEIRA, C. M. C.; MENDONÇA, C. L.; DUARTE, M. D.; BARBOSA, J. D. Etiologia e perfil de sensibilidade de bactérias isoladas de ovelhas com mastite na região nordeste do estado do Pará. Pesquisa Veterinária Brasileira. v.30, n.12, p.1043-1048, 2010.

SPINOSA, H. S. Antibióticos: tetraciclinas e cloranfenicol, In: Ibid. (Ed.), Farmacologia Aplicada à Medicina Veterinária. Guanabara Koogan, São Paulo, p.368-371, 1996.

SOUZA, G.N.; BRITO, J.R.F.; MOREIRA, E.C. et al. Fatores de risco para alta contagem de células somáticas do leite do tanque em rebanhos leiteiros da Zona da Mata de Minas Gerais, Brasil. Arquivo Brasileiro de Medicina Veterinária e Zootecnia, v.57, supl.2, p.251-260, 2005.

SOUZA, M. R.; SANTOS, L. M. ROCHA, J. R. Resistência dos microrganismos causadores de mastite no gado leiteiro da região de Garça S.P. frente a seis antimicrobianos. Revista Científica Eletrônica de Medicina Veterinária. n.11, 2008. Disponível em: http://www.revista.inf.br/veterinaria11/artigos/edic-vi-n11-Art07.pdf. Acesso em 31 de julho de 2010. 